\title{
Reliability of three-dimensional color flow Doppler and two-dimensional pulse wave Doppler transthoracic echocardiography for estimating cardiac output after cardiac surgery
}

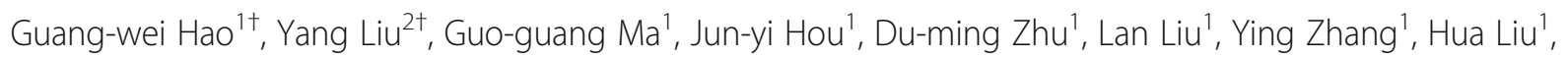
Ya-min Zhuang ${ }^{1}$, Zhe Luo ${ }^{1}$, Guo-wei Tu', Xiao-mei Yang ${ }^{1 *}$ and Hai-yan Chen ${ }^{2 *}$

\begin{abstract}
Background: Three-dimensional color flow Doppler (3DCF) is a new convenient technique for cardiac output (CO) measurement. However, to date, no one has evaluated the accuracy of 3DCF echocardiography for CO measurement after cardiac surgery. Therefore, this single-center, prospective study was designed to evaluate the reliability of three-dimensional color flow and two-dimensional pulse wave Doppler (2D-PWD) transthoracic echocardiography for estimating cardiac output after cardiac surgery.

Methods: Post-cardiac surgical patients with a good acoustic window and a low dose or no dose of vasoactive drugs (norepinephrine $<0.05 \mu \mathrm{g} / \mathrm{kg} / \mathrm{min}$ ) were enrolled for CO estimation. Three different methods (third generation FloTracNigileo ${ }^{\mathrm{TM}}$ [FTN] system as the reference method, 3DCF, and 2D-PWD) were used to estimate CO before and after interventions (baseline, after volume expansion, and after a dobutamine test).

Results: A total of 20 patients were enrolled in this study, and 59 pairs of CO measurements were collected (one pair was not included because of increasing drainage after the dobutamine test). Pearson's coefficients were 0.260 between the CO-FTN and CO-PWD measurements and 0.729 between the CO-FTN and CO-3DCF measurements. Bland-Altman analysis showed the bias between the absolute values of CO-FTN and CO-PWD measurements was $-0.6 \mathrm{~L} / \mathrm{min}$ with limits of agreement between $-3.3 \mathrm{~L} / \mathrm{min}$ and $2.2 \mathrm{~L} / \mathrm{min}$, with a percentage error (PE) of $61.3 \%$. The bias between COFTN and CO-3DCF was $-0.14 \mathrm{~L} / \mathrm{min}$ with limits of agreement between $-1.42 \mathrm{~L} / \mathrm{min}$ and $1.14 \mathrm{~L} / \mathrm{min}$, with a PE of 29.9\%. Four-quadrant plot analysis showed the concordance rate between $\triangle$ CO-PWD and $\Delta$ CO-3FTN was 93.3\%.

Conclusions: In a comparison with the FTN system, 3DCF transthoracic echocardiography could accurately estimate $\mathrm{CO}$ in post-cardiac surgical patients, and the two methods could be considered interchangeable. Although 2D-PWD echocardiography was not as accurate as the 3D technique, its ability to track directional changes was reliable.
\end{abstract}

Keywords: Three-dimensional color flow doppler, Two-dimensional pulse wave doppler, Cardiac output, Cardiac surgery

\footnotetext{
*Correspondence: yang.xiaomei@zs-hospital.sh.cn; chenhaiyan212@126.com

${ }^{\dagger}$ Guang-wei Hao and Yang Liu contributed equally to this work.

'Department of Critical Care Medicine, Zhongshan Hospital, Fudan University,

No. 180 Fenglin Road, Xuhui District, Shanghai 200032, People's Republic of

China

2Department of Echocardiography, Zhongshan Hospital, Fudan University,

No. 180 Fenglin Road, Xuhui District, Shanghai 200032, People's Republic of

China
}

(c) The Author(s). 2019 Open Access This article is distributed under the terms of the Creative Commons Attribution 4.0 International License (http://creativecommons.org/licenses/by/4.0/), which permits unrestricted use, distribution, and reproduction in any medium, provided you give appropriate credit to the original author(s) and the source, provide a link to the Creative Commons license, and indicate if changes were made. The Creative Commons Public Domain Dedication waiver (http://creativecommons.org/publicdomain/zero/1.0/) applies to the data made available in this article, unless otherwise stated. 


\section{Background}

Hemodynamic optimization has been shown to improve postoperative outcomes for moderate- and high-risk patients [1] and for cardiac surgical patients [2]. Cardiac output (CO) monitoring plays an important role in hemodynamic optimization, and the gold standard method for $\mathrm{CO}$ measurement is thermodilution through a pulmonary artery catheter (PAC) [3]. However, this method is invasive, expensive, and time-consuming [4], and the effectiveness of this device in cardiac surgical patients is controversial [5]. A FloTrac/Vigileo ${ }^{\text {тs }}$ (FT/V) system is a less invasive technique for $\mathrm{CO}$ monitoring than PAC, and the reliability of the third generation FT/V system for $\mathrm{CO}$ measurement is excellent in patients with normal systemic vascular resistance $[6,7]$.

Echocardiography is a noninvasive, convenient platform for measuring CO. [8] It is very useful in hemodynamic monitoring and is recommended by experts to direct fluid management of patients in shock [9]. However, current evidence does not prove its accuracy, or even its ability to track directional changes. Moreover, most previous studies mainly focused on the accuracy of two-dimensional (2D) techniques [10]. Three-dimensional (3D) techniques for $\mathrm{CO}$ evaluation should be more accurate than $2 \mathrm{D}$ ones because $3 \mathrm{D}$ echocardiography can more accurately evaluate the aortic root and aortic valve area [11-16]. 3D color flow Doppler (3DCF) is a new technique that is more convenient than traditional $3 \mathrm{D}$ echocardiography because it does not require reconstruction. However, to date, no one has evaluated the accuracy of 3DCF echocardiography for $\mathrm{CO}$ measurement after cardiac surgery. Therefore, this single-center, prospective study was designed to evaluate the agreement between $\mathrm{CO}$ measured by the third generation FloTrac/Vigileo ${ }^{\mathrm{Tm}}$ system as a reference method and $\mathrm{CO}$ measured by 3DCF and 2D echocardiography in post-cardiac surgical, hemodynamically stable patients.

\section{Methods}

This study was approved by the Ethics Committee of Zhongshan Hospital (Shanghai, China), which is affiliated with Fudan University (No. B2017-139). Informed consent was obtained from all study participants.

\section{Patient selection}

This single center, prospective study was conducted in adult cardiac surgical patients at the Zhongshan Hospital of Fudan University from 1 May to 31 May, 2018. In our hospital, all cardiac surgical patients were routinely transferred to the cardiac surgical intensive care unit with tracheal intubation after surgery. After admission, research personnel screened all patients for enrollment. The inclusion criteria were: 1) cardiac surgical patient; 2) good acoustic window; and 3) low dose or no dose of vasoactive drugs. The exclusion criteria were: 1) age $<18$ and $>80$ years; 2) aortic valve disease; 3) arrhythmias, extrasystole included; and 4) preoperative ejection fraction $<0.4$.

Enrolled patients were sedated via propofol and remifentanil for the duration of CO measurements. No inspiratory efforts were observed and no muscular blocking agents were used in this study. Patients were ventilated using intermittent positive pressure ventilation. The ventilatory parameters were set up as follows: tidal volume: $6-8 \mathrm{~mL} / \mathrm{kg}$ predicted body weight; positive end-expiratory pressure: $5 \mathrm{cmH}_{2} \mathrm{O}$; respiratory rate: 12-16 breaths/minute; fraction of inspired oxygen 50$100 \%$. These parameters were adjusted to meet the goal of $\mathrm{PaCO}_{2} \leq 45 \mathrm{mmHg}$ and oxygen saturation $\left(\mathrm{SaO}_{2}\right)>$ $96 \%$. Both the dose of sedatives and the parameters of ventilation were unchanged in the duration of this study.

\section{Measurements}

After the intensivists and echocardiography experts confirmed the enrollment, the FloTrac pressure transducer was connected to the radial artery catheter of each patient and the Vigileo $^{\mathrm{Tm}}$ monitor (third version). 2D images were acquired using the Siemens Acuson SC2000 Prime ultrasound system with a 4V1c transducer (1.254.5 MHz), as shown in Fig. 1. Diameters of the left ventricular outflow tract (LVOT) were measured in the parasternal left ventricular long axis view during the early phase of ventricular systole. In routine practice, LVOT velocity-time integrals (VTIs) could be acquired in the apical five chamber view or the apical long axis view. In this study we adopted the apical long axis view so that the aorta can also be displayed to ensure the position of doppler sample. LVOT VTI was automatically measured for three consecutive beats and averaged. Cardiac output was calculated using the LVOT diameter, LVOT VTI, and heart rate (HR) in line with the previously mentioned guidelines [8].

3D color flow Doppler images were acquired using the Siemens Acuson SC2000 ${ }^{\mathrm{Tm}}$ Prime ultrasound system with a 4Z1c (1.5-3.5 MHz) volume imaging transducer, as shown in Fig. 2. At least two sets of three consecutive cardiac cycles were obtained in the apical long axis view. The color Doppler scale was adjusted to avoid aliasing. The depth and color Doppler region of interest were optimized to maximize the color volume rates while ensuring that the complete LVOT as well as a part of the aortic root were included. During acquisition, two reference planes were simultaneously displayed at the same time. Digital images were recorded and analyzed using validated offline software (Siemens Medical Solutions) as follows: (1) with the aortic valve (AV) at the center, the reference images were rotated and adjusted to clearly show the region of interest from the LVOT to the proximal part of the aorta; (2) systole, diastole, and the timing of AV opening (AVO) and closing (AVC) were automatically 


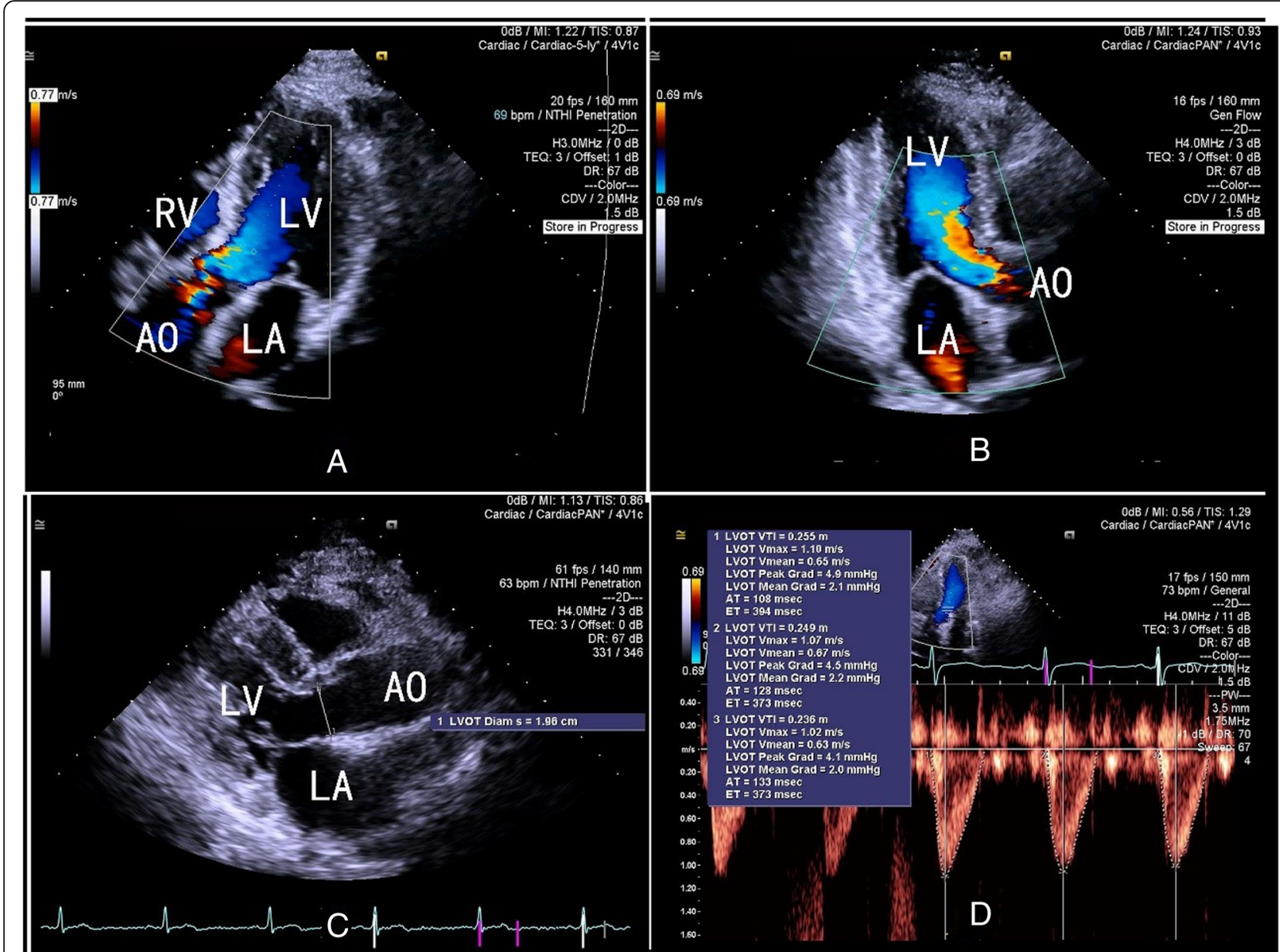

Fig. 1 CO assessment using 2D-PWD transthoracic echocardiography. Cardiac output was calculated using the LVOT diameter, LVOT VTI, and heart rate. In routine practice, LVOT velocity-time integrals (VTIs) could be acquired in the apical five chamber view (panel a) or apical long axis view (panel b). Diameters of the left ventricular outflow tract (LVOT) were measured in the parasternal left ventricular long axis view during the early phase of ventricular systole (panel c). LVOT VTI was automatically measured for three consecutive beats and averaged (panel d). RV, right ventricle; LV, left ventricle; LA, left atrium; $A O$, aorta

recognized by the software according to the ECG; the timing of AVO and AVC can be manually adjusted by reviewing the loops frame by frame; (3) during systole a frame was selected when the LVOT was fully filled with a color Doppler signal, and the software then automatically placed a hemisphere sampling plane in the LVO; (4) the angle of the sampling plane in the LVOT was manually adjusted so that the 3D volume color flow passed vertically through it and the size of the sampling plane was adjusted according to the cross-section of the $3 \mathrm{D}$ volume color flow so that it was just big enough for all outflow color signals to pass through; (5) the sampling plane automatically tracked the plane of interest in the left ventricular outflow tract throughout the whole cardiac cycle; and (6) the software generated flow-time curves of three consecutive cardiac cycles, and then calculated LVOT stroke volume and $\mathrm{CO}$ according to the area under the curves.
The echocardiograph experts were blinded to the hemodynamic variables recorded by the FloTrac/Vigileo ${ }^{\text {tw }}$ system (these were collected by the intensivist). Systolic, diastolic, and mean arterial pressures and HR were recorded by the real-time bedside monitor. Central venous pressure was recorded through the jugular vein catheter.

\section{Data collection}

The following data were recorded for each patient: (1) baseline demographic data (age, gender, and body mass index); (2) patient's degree of disease severity (Acute Physiology and Chronic Health Evaluation II [APACHE II] score and European system for cardiac operative risk evaluation [EuroSCORE]); (3) type of surgery (mitral/tricuspid valve replacement, off-pump coronary artery bypass graft [OPCABG], cardiac tumor resection, repair of atrial septal defect); (4) blood gas parameters before enrollment ( $\mathrm{pH}, \mathrm{pCO}_{2}, \mathrm{HCO}_{3}{ }^{-}, \mathrm{pO}_{2}$, lactate, and hemoglobulin); (5) 


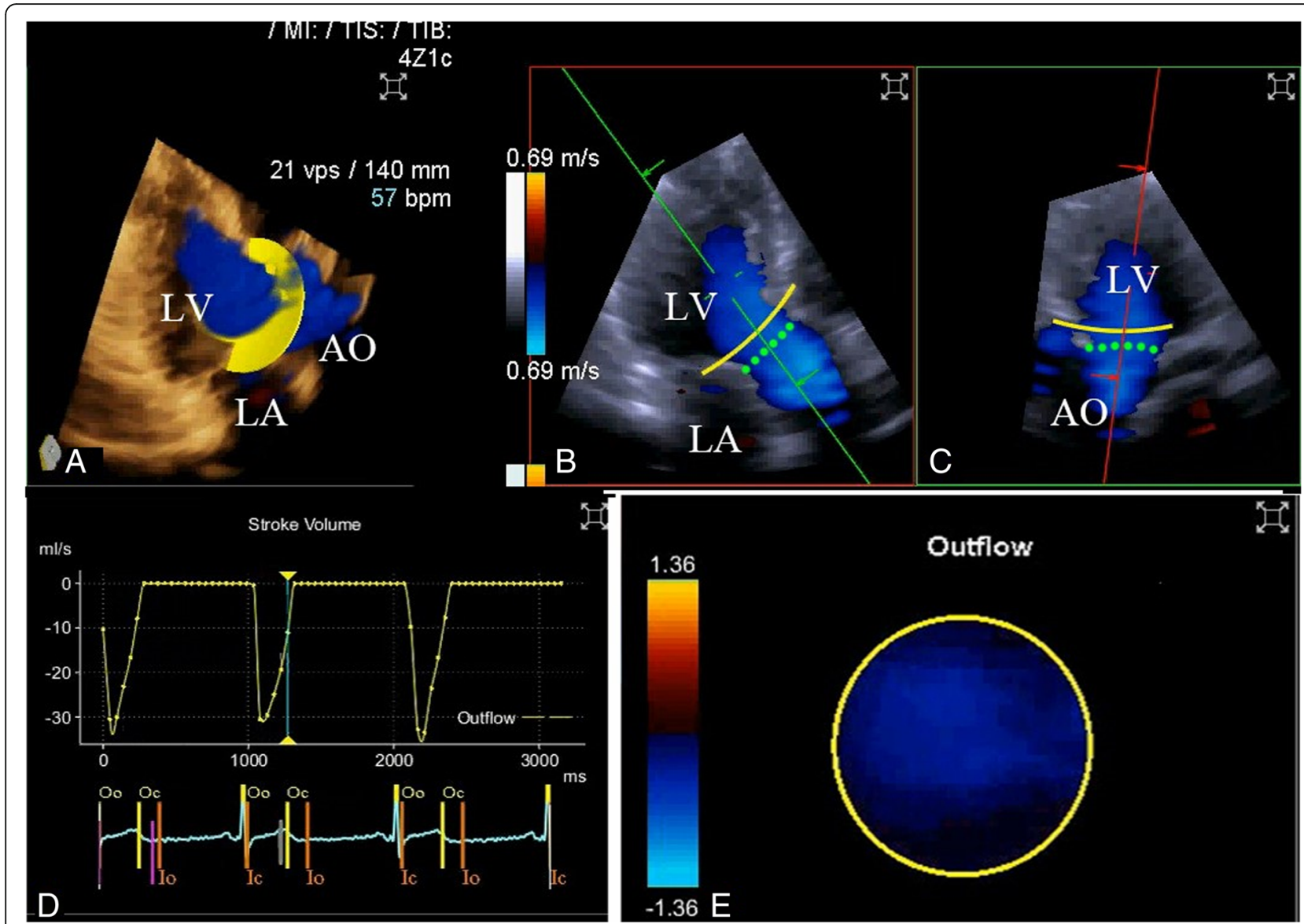

Fig. 2 CO assessment using 3DCF transthoracic echocardiography. 3DCF images were obtained in the apical long axis view (panel a). With the aortic valve (AV) at the center (green dot line in panel $\mathbf{b}$ and $\mathbf{c}$ ), the reference images were rotated and adjusted to clearly show the region of interest from the left ventricular outflow tract to the proximal part of the aorta; systole, diastole, timing of AV opening (AVO) and closing (AVC) were automatically recognized by the software according to the ECG (panel $\mathbf{d}$ ); panels $\mathbf{a}$ and $\mathbf{e}$ show that the 3D volume color flow passes vertically through the sampling plane (the yellow line in panels $\mathbf{b}$ and $\mathbf{c}$, the yellow plate in panel $\mathbf{a}$ ), and the size of the sampling plane is just big enough for all of the outflow color signals to pass through; panel $\mathbf{d}$ shows the flow-time curves of three consecutive cardiac cycles generated by the software

preoperative echocardiographic parameters (left ventricular ejection fraction [LVEF]); and (6) hemodynamic data at baseline ( $\mathrm{T} 0$, in a supine position with the head elevated to $30^{\circ}$ ), after volume loading (T1, $250 \mathrm{~mL} 0.9 \%$ $\mathrm{NaCl}$ solution infused in $10 \mathrm{~min}$ ) and after dobutamine testing (T2, $2 \mu \mathrm{g} / \mathrm{kg} / \mathrm{min}$ dobutamine infusion for about $15 \mathrm{~min})$. The hemodynamic data collected in this study included: HR, systolic blood pressure (SBP), diastolic blood pressure (DBP), mean arterial pressure (MAP), central venous pressure (CVP), cardiac index $(\mathrm{CI})$, stroke volume (SV), stroke volume variation (SVV), and CO. (7) echocardiography related data at different time points: CO, SV, VTI and LVEF.

\section{Statistical methods}

Normality was assessed using the Kolmogorov-Smirnov test for all data. Continuous variables are given as means \pm SD while categorical variables are reported as adjusted proportions. Comparisons of hemodynamic variables (continuous variables) between different time points were performed by paired Student's $t$-test or paired Wilcoxon's test, as appropriate. Differences between categorical variables were compared using the chi-square test or Fisher's exact test when necessary. Cardiac outputs collected from echocardiography (PWD and 3DCF) were each compared with that from FloTrac using a correlation analysis and by calculating Pearson's coefficient, expressed as the $\mathrm{r}$ value. Agreements of $\mathrm{CO}$ measured by the different methods were determined by Bland-Altman analysis, with assessment of the bias as the mean difference between methods. The limits of agreement (LoA) were calculated as the mean \pm 1.96 SD from the bias, defining the range in which $95 \%$ of the values were expected to fall [17]. The percentage error (PE) was calculated as $1.96 \mathrm{SD}$ of the bias of the methods divided by the mean $\mathrm{CO}$ from the two methods, as proposed by Critchley and Critchley, 
and the two methods could be used interchangeably if the PE was less than $30 \%$ [18]. Trending ability was assessed by analyzing $\triangle \mathrm{CO}$ values on a 4-quadrant plot with concordance. Exclusion zones of $15 \%$ were used, as $\Delta C O$ data with smaller changes represent a statistical noise component, and a concordance rate of $>92 \%$ indicates good trending according to Critchley and colleagues [19]. For all tests, a $p$ value $<0.05$ was considered statistically significant. Statistical analyses were performed using SPSS 22.0 software (IBM Corporation, NY, USA), GraphPad Prism 5.0, and MedCalc 15.6.1.0 software (Mariakerke, Belgium).

\section{Results}

\section{Demographic and clinical characteristics of enrolled patients}

Demographic and clinical characteristics were summarized in Table 1. Of the 20 post-cardiac surgical patients (seven males, 13 females) enrolled in this study, only three needed low doses of norepinephrine $(<0.05 \mu \mathrm{g} / \mathrm{kg} / \mathrm{min})$ to maintain their blood pressure. A total of 59 pairs of $\mathrm{CO}$ measurements were collected between the different methods (one patient's drainage increased after the infusion of dobutamine). The mean age of the enrolled patients was $62 \pm 9$ years, and the mean body mass index was $24 \pm 4 \mathrm{~kg} / \mathrm{m}^{2}$. The mean APACHE II score was $7 \pm 2$,

Table 1 Baseline characteristics of the patients $(n=20)$

\begin{tabular}{|c|c|}
\hline Characteristic & Value \\
\hline \multicolumn{2}{|l|}{ Patient } \\
\hline Age (years) & $62 \pm 9$ \\
\hline Male sex, $n(\%)$ & $7(35)$ \\
\hline BMI (kg/m2) & $24 \pm 4$ \\
\hline EurOSCORE & $4 \pm 2$ \\
\hline APACHE ॥ & $7 \pm 2$ \\
\hline LVEF (\%) & $61 \pm 10$ \\
\hline \multicolumn{2}{|c|}{ Cardiac surgery category, $n$ (\%) } \\
\hline OPCABG & $4(20)$ \\
\hline Tumor & $3(15)$ \\
\hline ASD & $1(5)$ \\
\hline Mitral/tricuspid valve & $12(60)$ \\
\hline \multicolumn{2}{|l|}{ Blood gas } \\
\hline $\mathrm{PH}$ & $7.41 \pm 0.04$ \\
\hline $\mathrm{PCO}_{2}(\mathrm{mmHg})$ & $36.0 \pm 3.9$ \\
\hline $\mathrm{HCO}_{3}^{-}(\mathrm{mmHg})$ & $22.0 \pm 1.7$ \\
\hline $\mathrm{PO}_{2}(\mathrm{mmHg})$ & $180.2 \pm 54.6$ \\
\hline Lactate (mmol/L) & $2.0 \pm 1.1$ \\
\hline $\mathrm{Hb}(\mathrm{g} / \mathrm{dL})$ & $9.9 \pm 1.9$ \\
\hline
\end{tabular}

Abbreviations: APACHE Acute Physiology and Chronic Health Evaluation, ASD atrial septal defect, $B M I$ body mass index, $C A B G$ coronary artery bypass graft, EuroSCORE European system for cardiac operative risk evaluation, $\mathrm{Hb}$ hemoglobulin, LVEF left ventricular ejection fraction while the mean EuroSCORE was $4 \pm 2$. The mean LVEF before surgery was $61 \% \pm 10 \%$. The most common surgical treatment in this study was mitral/tricuspid valve surgery (12 patients, 60\%); other surgical treatments included coronary artery bypass graft (four patients, $20 \%$ ), resection of a cardiac tumor (three patients, 15\%), and repair of an atrial septal defect (one patient, 5\%). All patients were in sinus rhythm and had no severe metabolic abnormalities that had an influence on blood pressure or hemorrhage after surgery.

\section{Hemodynamic data and echocardiograph related parameters before and after intervention}

Hemodynamic parameters at different time points were summarized in Table 2. CO, CI, SV, and SVV were recorded using the FT/V system. There were no significant changes in SBP, DBP, MAP, CO, CI, or SVV after volume expansion; however, SV and CVP increased while HR decreased after volume expansion. After $15 \mathrm{~min}$ of dobutamine testing, HR, SBP, DBP, MAP, CO, CI, and SV all significantly increased, while CVP and SVV did not change significantly. At each time point, echocardiography related parameters were collected and the results were shown in Table 3.

\section{Accuracy of CO-PWD and CO-3DCF, compared with CO-FT/N}

Considering all pairs of measurements performed in this study $(n=59)$, Pearson's coefficients were 0.260 between CO-FT/V and CO-PWD and 0.729 between CO-FT/V and CO-3DCF. Bland-Altman analysis showed the bias between the absolute values of $\mathrm{CO}-\mathrm{FT} / \mathrm{V}$ and CO-PWD was $-0.6 \mathrm{~L} / \mathrm{min}$ with limits of agreement between $-3.3 \mathrm{~L} / \mathrm{min}$ and $2.2 \mathrm{~L} / \mathrm{min}$, with a PE of $61.3 \%$. The bias between CO-FT/V and CO-3DCF was $-0.14 \mathrm{~L} /$ min with limits of agreement between $-1.42 \mathrm{~L} / \mathrm{min}$ and $1.14 \mathrm{~L} / \mathrm{min}$, with a PE of $29.9 \%$. The comparisons

Table 2 Hemodynamic data $(n=20)$

\begin{tabular}{llll}
\hline & T0 & T1 & T2 \\
\hline HR (beats/min) & $71 \pm 12$ & $68 \pm 11^{\mathrm{a}}$ & $79 \pm 15^{\mathrm{b}, \mathrm{c}}$ \\
SBP (mmHg) & $111 \pm 15$ & $113 \pm 18$ & $121 \pm 21^{\mathrm{b}, \mathrm{c}}$ \\
DBP (mmHg) & $57 \pm 8$ & $58 \pm 8$ & $65 \pm 11^{\mathrm{b}, \mathrm{c}}$ \\
MAP (mmHg) & $74 \pm 11$ & $76 \pm 11$ & $87 \pm 14^{\mathrm{b}, \mathrm{c}}$ \\
CVP (mmHg) & $10 \pm 3$ & $11 \pm 3^{\mathrm{a}}$ & $11 \pm 3$ \\
CO (L/min) & $3.9 \pm 1.0$ & $4.0 \pm 0.7$ & $5.1 \pm 1.6^{\mathrm{b}, \mathrm{c}}$ \\
Cl (L/min/m2) & $2.4 \pm 0.5$ & $2.4 \pm 0.4$ & $3.1 \pm 0.8^{\mathrm{b}, \mathrm{c}}$ \\
SV (ml) & $55 \pm 13$ & $59 \pm 12^{\mathrm{a}}$ & $64 \pm 14^{\mathrm{c}}$ \\
SW (\%) & $10 \pm 4$ & $9 \pm 5$ & $8 \pm 4$
\end{tabular}

${ }^{\mathrm{a}} p<0.05$ between $\mathrm{T} 0$ and $\mathrm{T} 1 ;{ }^{\mathrm{b}} p<0.05$ between $\mathrm{T} 1$ and $\mathrm{T} 2 ;{ }^{c} p<0.05$ between $\mathrm{T} 2$ and TO. $\mathrm{Cl}$ cardiac index, $\mathrm{CO}$ cardiac output, CVP central venous pressure, $D B P$ diastolic blood pressure, $H R$ heart rate, $M A P$ mean arterial pressure, $S B P$ systolic blood pressure, SV stroke volume, SVV stoke volume variation 
Table 3 Echocardiography related data $(n=20)$

\begin{tabular}{llll}
\hline Characteristics & \multicolumn{1}{c}{ T0 } & \multicolumn{1}{c}{ T1 } & \multicolumn{1}{c}{ T2 } \\
\hline 3DCF & & & \\
CO (L/min) & $4.05 \pm 0.88$ & $4.23 \pm 0.86$ & $5.22 \pm 1.8$ \\
SV (ml) & $55 \pm 14$ & $58 \pm 12$ & $63 \pm 16$ \\
2D-PWD & & & \\
CO (L/min) & $4.63 \pm 1.37$ & $4.81 \pm 1.50$ & $5.23 \pm 1.38$ \\
SV (ml) & $65 \pm 21$ & $70 \pm 22$ & $68 \pm 23$ \\
VTI (cm) & $19.02 \pm 5.43$ & $20.85 \pm 6.15$ & $20.66 \pm 6.09$ \\
LVEF (\%) & $62 \pm 10$ & $61 \pm 10$ & $62 \pm 11$ \\
\hline A & &
\end{tabular}

Abbreviations: 3DCF 3 dimensional color flow, CO cardiac output, SV stroke volume, 2D-PWD 2 dimensional pulse wave doppler, VTI velocity time integral, LVEF left ventricular ejection fraction

between CO-FT/V and CO-PWD, CO-FT/V and CO3DCF are summarized in Fig. 3.

\section{Tracking of the trending ability of CO-PWD}

The results of the four quadrant-plot analysis are shown in Fig. 4. As the paired Student's $t$-test showed no significant difference in $\mathrm{CO}$ between $\mathrm{T} 0$ and $\mathrm{T} 1$, we did not include the $\triangle \mathrm{CO}$ data before and after volume expansion in the analysis. Among the 39 pairs of $\Delta C O$ data induced by the dobutamine test or volume expansion + dobutamine test (T0 to $\mathrm{T} 2$ and $\mathrm{T} 1$ to $\mathrm{T} 2$ ), 30 pairs exhibited a more than $15 \%$ change. The concordance rate between $\triangle \mathrm{CO}-\mathrm{PWD}$ and $\triangle \mathrm{CO}-3 \mathrm{DCF}$ was $93.3 \%$.

\section{Discussion}

In this prospective study evaluating the reliability of $\mathrm{CO}$ measured by 3DCF and 2D-PWD transthoracic echocardiography in post-cardiac surgical, hemodynamically stable patients, we found that $\mathrm{CO}$ values measured by $3 \mathrm{DCF}$ echocardiography and FT/V could be considered interchangeable with a PE of $29.9 \%$. Although the precision of 2D-PWD echocardiography in measuring $\mathrm{CO}$ was not as good as that of the 3DCF technique, its ability to track changes in $\mathrm{CO}$ in different clinical settings was reliable. To the best of our knowledge, this is the first study to evaluate the accuracy of the 3DCF technique in measuring $\mathrm{CO}$ after cardiac surgery.

Hemodynamic instability is very common in the early period after cardiac surgery, either because of preoperative status or intraoperative events such as cardiopulmonary bypass [20, 21]. Today, the transthoracic Doppler technique is frequently used because of its convenience, real time measurement, and noninvasiveness [22, 23]. Beside these factors, the accuracy of hemodynamic monitoring is one of the most important concerns of physicians. However, studies concerning the accuracy of 3DCF echocardiography in $\mathrm{CO}$ measurement after cardiac surgery have been limited. Due to these considerations, the authors decided to evaluate the accuracy of 3DCF and 2D-PWD transthoracic echocardiography.

In this study, the comparison between the absolute values of CO-FT/V and CO-PWD showed a low bias,
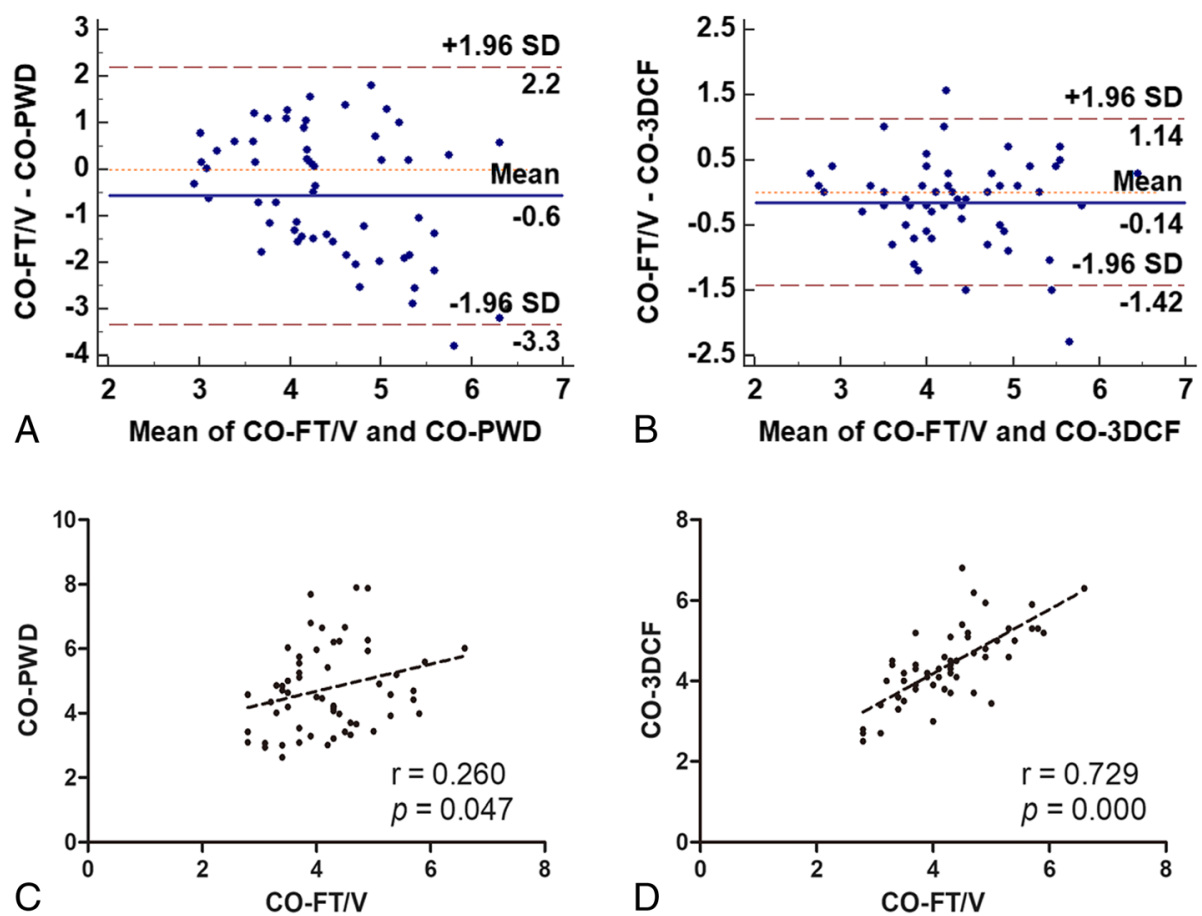

Fig. 3 Bland and Altman plot (a and $\mathbf{b}$ ) and linear regression plot with Pearson's coefficient (c and $\mathbf{d}$ ) of the cardiac output measured with FT/N versus $2 \mathrm{D}-\mathrm{PWD}$ and $3 \mathrm{DCF}$ echocardiography techniques 


\section{Four-Quadrant Plot}

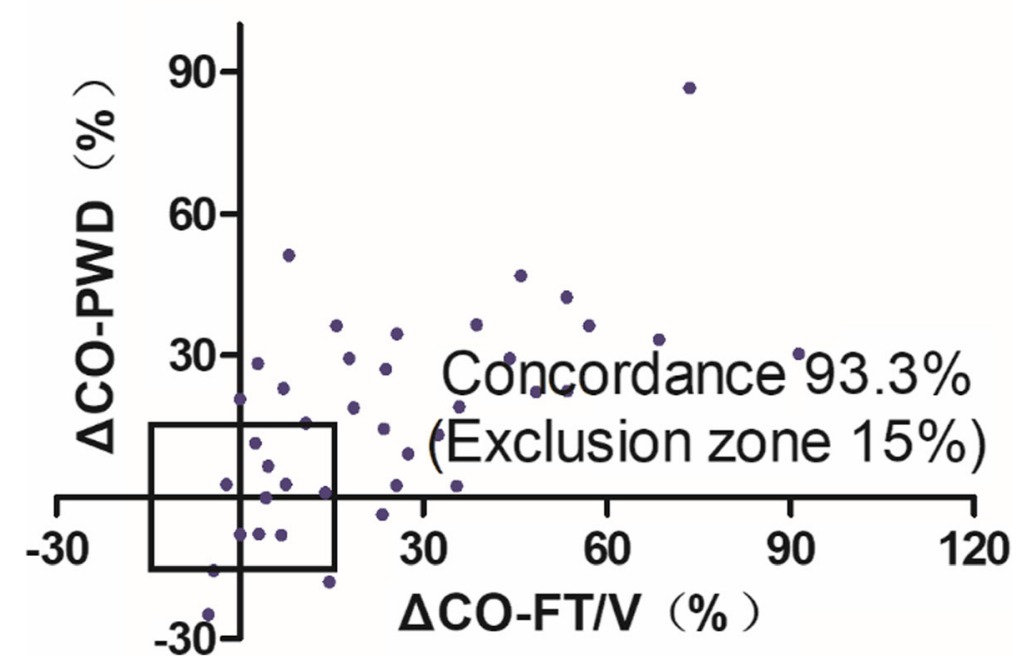

Fig. 4 Trending ability of the 2D-PWD echocardiography technique against CO measured by the FTN system based on four-quadrant concordance analysis

but with an unacceptably high LoA and PE (61.3\%). This may be due to the inherent limitations of the pulse wave Doppler technique [24, 25]. Firstly, the Doppler technique is angle-dependent and involves the assumption of a uniform flow profile within the LVOT. Secondly, the measurement of the diameter of the LVOT and the assumption of its cross-sectional morphology further reduce the accuracy of the measurement. Mik et al. systemically reviewed studies of $\mathrm{CO}$ measurements by echocardiography vs. thermodilution and found that most studies exhibited a small bias, wide LoA, and high $\mathrm{PE}$ between the two techniques, but the echocardiography technique was reliable in tracking directional changes in CO. [10] In our study, the four-quadrant plot analysis revealed good concordance $(93.3 \%)$ between $\triangle \mathrm{CO}-\mathrm{PWD}$ and $\Delta \mathrm{CO}-\mathrm{FT} / \mathrm{V}$, further confirming the ability to track directional changes in $\mathrm{CO}$ using the 2D-PWD echocardiography technique.

The percentage error between CO-3DCF and CO-FT/V was $29.9 \%$, which meant that the two methods could be used interchangeably according to Critchley et al. [18] CO was slightly underestimated by the 3DCF technique, with a mean bias of $-0.14 \mathrm{~L} / \mathrm{min}$ and LoA between $-1.42 \mathrm{~L} /$ min and $1.14 \mathrm{~L} / \mathrm{min}$. Shimada et al. studied 46 different hemodynamic states in five open-chest pigs to explore the feasibility and accuracy of 2D and 3D color flow Doppler quantification for LVOT SV. SV derived from sonomicrometry was used as the reference value. In their study, the 3DCF method showed a smaller bias and better correlation with the sonomicrometry method than the 2D method [26]. Thavendiranathan et al. also reported real-time volume color flow Doppler is superior to $2 \mathrm{D}$ transthoracic echocardiography for the measurement of LV SV using cardiac magnetic resonance imaging as the standard method [27]. 2D techniques involve a multistep process with multiple assumptions: firstly, the small errors in measurements of LVOT are squared in the calculation of LVOT area; secondly, the geometric variation of the LVOT cross-sectional area is neglected; thirdly, the LVOT diameter and its flow velocity are acquired in two different views of two different cycles; and finally, flow velocities vary within the LVOT cross-sectional area. Gated 3D echocardiography eliminates the velocity and geometric assumptions of the 2D method; however, it requires reconstruction of datasets over seven to 14 cardiac cycles. Thus, flow quantification does not truly represent a single beat. Among the three methods, the 3DCF technique not only addresses the above limitations of $2 \mathrm{D}$ echocardiography, but also eliminates the need for reconstruction required under gated 3D echocardiography. It can display full volume, B mode, and color Doppler for each single cardiac cycle with a pyramid up to $90^{\circ} \times 90^{\circ}$, and quantify regurgitation, cardiac function, and shunt $[27,28]$.

There were several limitations of this study. First, its sample size was small, and patients were enrolled because of their good acoustic windows. But not all post-cardiac surgical patients have good acoustic windows, which limits the usefulness of the conclusions in post-cardiac surgical patients. Second, we used a FloTrac/Vigileo ${ }^{\text {Tx }}$ (third generation) system as the reference method, not the gold standard thermodilution method. Although the patients enrolled were all in good condition and $\mathrm{CO}$ measured by the FT/V technique should be accurate in these patients as discussed before, there might still be some 
discrepancy from the true values. Third, the patients enrolled in this study only represented a subset of ICU patients after cardiac surgery, whether the 3D echocardiography technique adopted would have the same accuracy in all cardiac surgical patients needs further confirmation. Last, this was a single-center study and is subject to intrinsic limitations; a further multicenter study is needed to confirm our findings.

\section{Conclusions}

3DCF transthoracic echocardiography could accurately estimate $\mathrm{CO}$ in post-cardiac surgical patients compared with a FT/V system; the two methods could be considered interchangeable. Although 2D-PWD echocardiography was not as accurate as the 3DCF technique, its ability to track directional changes was reliable.

\begin{abstract}
Abbreviations
2D-PWD: Two-dimensional pulse wave Doppler; 3DCF: Three-dimensional color flow Doppler; APACHE II: Acute Physiology and Chronic Health Evaluation II; AV: Aortic valve; AVC: AV closing; AVO: AV opening; CABG: Coronary artery bypass graft; Cl: Cardiac index; CO: Cardiac output; CVP: Central venous pressure; DBP: Diastolic blood pressure; EuroSCORE: European system for cardiac operative risk evaluation; FT/ V: FloTrac/Nigileo ${ }^{\text {TM}}$; HR: Heart rate; LoA: Limits of agreement; LVEF: Left ventricular ejection fraction; LVOT: Left ventricular outflow tract; MAP: Mean arterial pressure; PE: Percentage error; SBP: Systolic blood pressure; SV: Stroke
\end{abstract} volume; SW: Stroke volume variation; VTIs: Velocity-time integrals

\section{Acknowledgements}

None.

\section{Funding}

This article was supported by grants from the research funds of the Zhongshan Hospital (2017ZSQN16).

\section{Availability of data and materials}

All data and material are available as needed.

\section{Authors' contributions}

$\mathrm{GH}, \mathrm{YL}$ contributed equally to this article. $\mathrm{GH}$, and $\mathrm{YL}$ performed the data collection and drafted the manuscript. $\mathrm{HC}$ and $\mathrm{YL}$ did the $\mathrm{CO}$ measurement by 3DCF and 2D-PWD transthoracic echocardiography. GM, JH, YZ, LL, HL and $Y Z$ reviewed studies for inclusion and extracted data. GT, DZ and ZL performed the analysis and helped draft the manuscript. $\mathrm{HC}$ and $\mathrm{XY}$ conceived the idea, participated in manuscript writing and revision. All authors have read and approved the final manuscript.

\section{Ethics approval and consent to participate}

We attest that all human studies in our centre have been reviewed by the appropriate ethics committee and have therefore been performed in accordance with the ethical standards. Informed consent was obtained from all study participants.

\section{Consent for publication}

All authors agreed with the content of this manuscript and its submission to Cardiovascular ultrasound.

\section{Competing interests}

The authors declare that they have no competing interests.

\section{Publisher's Note}

Springer Nature remains neutral with regard to jurisdictional claims in published maps and institutional affiliations.
Received: 8 November 2018 Accepted: 1 March 2019

Published online: 03 April 2019

\section{References}

1. Hamilton MA, Cecconi M, Rhodes A. A systematic review and meta-analysis on the use of preemptive hemodynamic intervention to improve postoperative outcomes in moderate and high-risk surgical patients. Anesth Analg. 2011;112(6):1392-402.

2. Goepfert MS, Reuter DA, Akyol D, Lamm P, Kilger E, Goetz AE. Goal-directed fluid management reduces vasopressor and catecholamine use in cardiac surgery patients. Intensive Care Med. 2007;33(1):96-103.

3. Thiele RH, Bartels K, Gan TJ. Cardiac output monitoring: a contemporary assessment and review. Crit Care Med. 2015;43(1):177-85.

4. Richard C, Monnet X, Teboul JL. Pulmonary artery catheter monitoring in 2011. Curr Opin Crit Care. 2011:17(3):296-302.

5. Joseph C, Garrubba M, Smith JA, Melder A. Does the use of a pulmonary artery catheter make a difference during or after cardiac surgery? Heart Lung Circ. 2018;27(8):952-60.

6. Suehiro K, Tanaka K, Matsuura T, Funao T, Yamada T, Mori T, et al. The Vigileo-FloTrac system: arterial waveform analysis for measuring cardiac output and predicting fluid responsiveness: a clinical review. J Cardiothorac Vasc Anesth. 2014:28(5):1361-74

7. Suehiro K, Tanaka K, Funao T, Matsuura T, Mori T, Nishikawa K. Systemic vascular resistance has an impact on the reliability of the Vigileo-FloTrac system in measuring cardiac output and tracking cardiac output changes. Br J Anaesth. 2013;111(2):170-7.

8. Quinones MA, Otto CM, Stoddard M, Waggoner A, Zoghbi WA. Recommendations for quantification of Doppler echocardiography: a report from the Doppler quantification task force of the nomenclature and standards Committee of the American Society of echocardiography. J Am Soc Echocardiogr. 2002;15(2):167-84

9. Cecconi M, De Backer D, Antonelli M, Beale R, Bakker J, Hofer C, et al. Consensus on circulatory shock and hemodynamic monitoring. Task force of the European Society of Intensive Care Medicine. Intensive Care Med. 2014;40(12):1795-815.

10. Wetterslev M, Moller-Sorensen H, Johansen RR, Perner A. Systematic review of cardiac output measurements by echocardiography vs. thermodilution: the techniques are not interchangeable. Intensive Care Med. 2016;42(8):1223-33.

11. Calleja A, Thavendiranathan P, Ionasec Rl, Houle H, Liu S, Voigt I, et al. Automated quantitative 3 -dimensional modeling of the aortic valve and root by 3-dimensional transesophageal echocardiography in normals, aortic regurgitation, and aortic stenosis: comparison to computed tomography in normals and clinical implications. Circ Cardiovasc Imaging. 2013;6(1):99-108.

12. Khaw AV, von Bardeleben RS, Strasser C, Mohr-Kahaly S, Blankenberg S, Espinola-Klein C, et al. Direct measurement of left ventricular outflow tract by transthoracic real-time 3D-echocardiography increases accuracy in assessment of aortic valve stenosis. Int J Cardiol. 2009;136(1):64-71.

13. Saitoh T, Shiota M, Izumo M, Gurudevan SV, Tolstrup K, Siegel RJ, et al. Comparison of left ventricular outflow geometry and aortic valve area in patients with aortic stenosis by 2-dimensional versus 3-dimensional echocardiography. Am J Cardiol. 2012;109(11):1626-31.

14. Ng AC, Delgado V, van der Kley F, Shanks M, van de Veire NR, Bertini M, et al. Comparison of aortic root dimensions and geometries before and after transcatheter aortic valve implantation by 2 - and 3-dimensional transesophageal echocardiography and multislice computed tomography. Circ Cardiovasc Imaging. 2010;3(1):94-102.

15. Doddamani S, Bello R, Friedman MA, Banerjee A, Bowers JH Jr, Kim B, et al. Demonstration of left ventricular outflow tract eccentricity by real time 3D echocardiography: implications for the determination of aortic valve area. Echocardiography. 2007;24(8):860-6.

16. Doddamani S, Grushko MJ, Makaryus AN, Jain VR, Bello R, Friedman MA, et al. Demonstration of left ventricular outflow tract eccentricity by 64 -slice multi-detector CT. Int J Cardiovasc Imaging. 2009;25(2):175-81.

17. Bland JM, Altman DG. Statistical methods for assessing agreement between two methods of clinical measurement. Lancet. 1986;1(8476):307-10.

18. Critchley LA, Critchley JA. A meta-analysis of studies using bias and precision statistics to compare cardiac output measurement techniques. J Clin Monit Comput. 1999:15(2):85-91.

19. Critchley LA, Lee A, Ho AM. A critical review of the ability of continuous cardiac output monitors to measure trends in cardiac output. Anesth Analg. 2010;111(5):1180-92. 
20. Stephens RS, Whitman GJ. Postoperative critical Care of the Adult Cardiac Surgical Patient. Part I: routine postoperative care. Crit Care Med. 2015;43(7): 1477-97.

21. St Andre AC, DelRossi A. Hemodynamic management of patients in the first 24 hours after cardiac surgery. Crit Care Med. 2005;33(9):2082-93.

22. Margale S, Marudhachalam K, Natani S. Clinical application of point of care transthoracic echocardiography in perioperative period. Indian J Anaesth. 2017;61(1):7-16.

23. Cornette J, Laker S, Jeffery B, Lombaard H, Alberts A, Rizopoulos D, et al. Validation of maternal cardiac output assessed by transthoracic echocardiography against pulmonary artery catheterization in severely ill pregnant women: prospective comparative study and systematic review. Ultrasound Obstet Gynecol. 2017;49(1):25-31.

24. Tsujino H, Jones M, Shiota T, Qin JX, Greenberg NL, Cardon LA, et al. Realtime three-dimensional color Doppler echocardiography for characterizing the spatial velocity distribution and quantifying the peak flow rate in the left ventricular outflow tract. Ultrasound Med Biol. 2001;27(1):69-74.

25. Kusumoto F, Venet T, Schiller NB, Sebastian A, Foster E. Measurement of aortic blood flow by Doppler echocardiography: temporal, technician, and reader variability in normal subjects and the application of generalizability theory in clinical research. J Am Soc Echocardiogr. 1995;8(5 Pt 1):647-53.

26. Shimada E, Zhu M, Kimura S, Streiff C, Houle H, Datta S, et al. Quantitative assessment of mitral inflow and aortic outflow stroke volumes by 3dimensional real-time full-volume color flow doppler transthoracic echocardiography: an in vivo study. J Ultrasound Med. 2015;34(1):95-103.

27. Thavendiranathan P, Liu S, Datta S, Walls M, Nitinunu A, Van Houten T, et al. Automated quantification of mitral inflow and aortic outflow stroke volumes by three-dimensional real-time volume color-flow Doppler transthoracic echocardiography: comparison with pulsed-wave Doppler and cardiac magnetic resonance imaging. J Am Soc Echocardiogr. 2012;25(1): $56-65$.

28. Son JW, Chang HJ, Lee JK, Chung HJ, Song RY, Kim YJ, et al. Automated quantification of mitral regurgitation by three dimensional real time full volume color Doppler transthoracic echocardiography: a validation with cardiac magnetic resonance imaging and comparison with two dimensional quantitative methods. J Cardiovasc Ultrasound. 2013;21(2):81-9.

Ready to submit your research? Choose BMC and benefit from:

- fast, convenient online submission

- thorough peer review by experienced researchers in your field

- rapid publication on acceptance

- support for research data, including large and complex data types

- gold Open Access which fosters wider collaboration and increased citations

- maximum visibility for your research: over $100 \mathrm{M}$ website views per year

At BMC, research is always in progress.

Learn more biomedcentral.com/submissions 